\title{
The Determinants of the Prevalence of Single Mothers: A Cross-Country Analysis
}

\author{
Libertad González \\ Universitat Pompeu Fabra
}

July 2005

\begin{abstract}
This paper examines the effect of public assistance, labor market and marriage market conditions on the prevalence of single mother families across countries and over time. A multinomial logit derived from a random utility approach is estimated using individuallevel data for 14 countries. I find evidence that increases in the level of public support are significantly and positively associated with a higher incidence of both never married and divorced mothers. The results also suggest that single mothers are more prevalent when female wages are lower. Higher male earnings and employment opportunities in a woman's marriage market appear to lead to fewer never married mothers, but more divorced mothers. Higher child support or alimony payments are associated with a higher prevalence of divorced mothers.
\end{abstract}

Keywords: Single mothers, marriage, fertility, welfare benefits, marriage markets.

JEL Codes: J12, J13, I38.

\footnotetext{
- Email at: libertad.gonzalez@upf.edu. Mailing address: Universitat Pompeu Fabra, Departamento de Economía y Empresa, Edificio Jaume I, Ramón Trias Fargas, 25-27, 08005 Barcelona, SPAIN. Phone: (34) 93542 2610. Fax: (34) 935421746.
} 


\section{Introduction}

The prevalence of single mother families increased dramatically in the United States during the past four decades. The proportion of all families with children that were headed by a single mother rose from 8 percent in 1960 to 24 percent in 2002 (US Census Bureau). Similar trends have been observed in other Western nations, such as Britain or Sweden. However, other countries, such as Italy, Japan or Spain, have remained at low levels of female headship, with less than 5 percent of all families with children being headed by a single mother during the 1990s.

Much research has been devoted to understanding the factors underlying this shift away from two-parent families in the United States. The main concern is that single motherhood seems to be associated with poverty and negative outcomes for children. ${ }^{1}$ In 2001, 42\% of single-mother households in the US were poor, compared with $8 \%$ of households headed by married parents (US Census Bureau 2001).

The likelihood of a woman becoming a single mother is undoubtedly affected by social, cultural and religious factors. It is also undeniable, however, that there are economic variables with a potential to influence fertility and partnership decisions, as economic theory has long emphasized. Most studies hypothesize one of the following alternative explanations for the rise in single mother families in the US: 1 . Welfare incentives (Murray 1984, Moffitt 1994, 1995, Hoynes 1997, Blau et al. 2004); 2. Increased economic opportunities for women (McLanahan 1994, Edlund 2005, Schmidt 2003); 3. Reduced supply of marriageable men (Wilson 1987), or a combination of those (Rosenzweig 1999, Schultz 1994, Willis 1999, Moffitt 2001, Neal 2004). ${ }^{2}$ None

\footnotetext{
${ }^{1}$ See Lerman (1996), McLanahan \& Sandefur (1994), and Krein \& Beller (1988) for examples of studies that address the effect of living in a single mother household on children's outcomes.

${ }^{2}$ See Akerlof, Yellen and Katz (1996) for an explanation based on changes in social norms.
} 
of these hypotheses alone is totally satisfactory, and no consensus has been reached on the subject to date.

This paper examines whether the above-mentioned factors are significant in explaining the variation in the prevalence of single mothers across countries and over time. I combine individual-level data for 14 countries from the Luxembourg Income Study (LIS) to examine the trends in single motherhood during the 1980s and 1990s. While previous studies of the prevalence of single mothers have focused on a single country, a multi-country analysis is especially attractive since the large variation in public support and labor market conditions across countries and over time provides an excellent source of identification for the effects of interest. Moreover, most previous studies either focused on overall rates of female headship, or addressed one part of the picture alone, mainly out-of-wedlock childbearing or marriage dissolution. I attempt to integrate these approaches by analyzing single motherhood as a whole while also taking into account the different routes that may lead to single motherhood. Finally, I estimate a structural model that stems directly from a random utility approach, as opposed to the common practice of estimating reduced form regressions, thus the results can be interpreted in terms of the underlying utilities, and allow for the simulation of different changes in benefit structures and labor market conditions.

The results show that public support, labor market and marriage market conditions do seem to be significantly associated with the incidence of single mother families across countries, and the effects are largely consistent with the predictions of the model. The evidence suggests that increases in the level of public support for single mothers are significantly and positively associated with a higher prevalence of both never married and divorced mothers. The results also show that single mothers are more prevalent when female wages are lower. Better marriage market conditions (higher male 
earnings and employment rates) seem to be associated with a lower incidence of never married mothers, but the association is positive with the number of divorced mothers. Finally, higher child support payments are associated with a higher prevalence of divorced mothers.

The remainder of this paper is organized as follows. I first briefly review some relevant previous work (section 2). Section 3 introduces the theoretical framework and emphasizes the channels through which the explanatory variables affect the relevant decisions. The following section describes the data set and the overall trends in the prevalence of single mother families across countries. Section 5 presents and discusses the results, and section 6 summarizes the main findings and concludes.

\section{A Brief Look at the Literature}

Many previous studies have attempted to estimate the effect of welfare benefits on fertility and marriage in the United States, with mixed results. ${ }^{3}$ These studies usually model the probability of being a female head as a function of individual and state characteristics, including welfare benefits. Most studies estimate cross-sectional regressions, which rely on interstate variation in benefits to identify the welfare effect (Schultz 1994). Some use more than one period and introduce state (or MSA) fixedeffects in order to control for omitted state variables (Hoynes 1997, Moffitt 1994, Blau et al. 2004). Some find significant effects (Schultz 1994, Rosenzweig 1999), and some find no effect at all (Moffitt 1994, Hoynes 1997).

The second set of variables that has been emphasized in the literature refers to economic independence of women, as measured by female wage levels and other

\footnotetext{
${ }^{3}$ See, for example, Danziger et alia 1982, Murray 1984, Ellwood and Bane 1985, Hoffman and Duncan 1988, Moffitt 1990, 1992, 1994, 1998, 2000, Fitzgerald 1991, Lundberg and Plotnick 1995, Jackson and Klerman 1996, Hoynes 1997, Lichter et al. 1997, Rosenzweig 1999, Blau et al. 2004, Neal 2004.
} 
indicators of female attachment to the labor force and employment opportunities. Some have suggested that access to higher income possibilities would enable women to support children on their own (Schmidt 2003, McLanahan 1994, Edlund 2005). ${ }^{4}$ Others, however, point out that the lack of economic opportunities may lower the perceived costs of out-of-wedlock childbearing, especially for very young women (Rich and Kim 2002, Duncan and Hoffman 1990). ${ }^{5}$ Wages could also show a negative correlation with the prevalence of single mothers if, as some have suggested, marriage is a normal good (Moffitt 2001, Oppenheimer 1994).

Finally, some studies attribute the increase in the prevalence of single mothers in the US to a reduced supply of marriageable men, especially at the bottom of the skill distribution. In other words, sex ratios and the supply of men with stable earnings prospects have a potential to influence partnership decisions. Some evidence has been provided that the supply of men as well as their earnings and employment prospects affect female marriage behavior (Wilson 1987, Angrist 2002, Wallace 2000, Brien 1997). Willis (1999) develops a theoretical framework that implies that out-of-wedlock childbearing should be more prevalent when females are in excess supply, and when the gains to marriage are small because male incomes are low. However, the fact that marriage market prospects affect marriage rates does not necessarily imply that they also affect single motherhood, as Neal (2004) points out.

Few studies have addressed the relationship between the above-mentioned variables and the cross-country variation in the prevalence of single mothers, and those that have

\footnotetext{
${ }^{4}$ For example, one of the testable implications of Schmidt's model is that "Higher female income, both in absolute terms as well as relative to that of men in a woman's marriage market, should increase the probability of a nonmarital birth" (Schmidt 2002). This hypothesis, however, is not confirmed by her empirical analysis. As for divorced single mothers, Sander (1985) concludes that "the divorce rate [in the US] is significantly and substantially affected by the earning ability of women in market worth". Lichter et al. (1997) briefly review a literature that "attribute(s) changing patterns in family formation to the improving employment circumstances of American women.”

${ }^{5}$ According to Rich and Kim (2002), "lack of economic opportunities may serve to lessen the perceived costs of engaging in early, nonmarital sexual activity". Duncan and Hoffman (1990) find that "women with the least to lose are most likely to have children during their teen years".
} 
done so have taken a merely descriptive approach. This is due in part to difficulties in finding reliable, high quality, comparable data for different countries.

Whiteford and Bradshaw (1994) and Bradshaw (1998) compare benefit systems in several countries, and their analysis hints at a possible association between the level of public support for single mother families and the prevalence of this type of household. ${ }^{6}$ However, their cross-tabulations do not include significance levels, they do not account for any other factors that may vary across countries, and they only consider one period, thus not being able to introduce country fixed effects.

\section{A Model of Family Formation}

\subsection{The Basic Model}

I propose a simple model that captures the relevant considerations in a minimal form. The model follows the spirit of the seminal work of Becker (Becker 1960, 1973, 1974, Becker et al. 1977, Becker and Barro 1988) in assuming that fertility and marriage decisions are the result of rational decision-making, in the sense that actions are influenced by the expected costs and benefits of the different choices available to the individual.

I assume that a woman derives utility from her own consumption, leisure time, bearing children, and marriage. She faces a time constraint such that she needs to distribute her time between work, leisure, and childcare. She chooses marital status and number of children to maximize her utility, given her time and budget constraints.

The fertility and partnership decisions are made jointly, so that, simplifying the fertility decision to a binary one, there are four possible outcomes: unmarried without

\footnotetext{
6 "The relationship between the structure of benefit systems facing lone parents and their individual behavior is clearly not straightforward. [Our evidence suggests that] most benefit systems are not neutral and can be expected to have the potential to affect incentives. Whether these incentives are translated into actual behavior is not at all clear, however.” (pp. 83-84, Whiteford and Bradshaw 1994).
} 
children $(j=1)$, unmarried with children $(j=2)$, married without children $(j=3)$, and married with children $(j=4)$. However, there is an exogenous chance that a marriage will be hit by a negative shock and dissolved. Therefore, once we account for the possibility of divorce (or widowhood), there are six possible outcomes (see figure 1). ${ }^{7}$

A woman $i$ in country $s$ and period $t$ is thus faced with this (static) utility maximization problem. The (expected) maximal utility that she can achieve by choosing alternative $j$ is denoted by $U_{\text {ist }}^{j}$. There are thus two distinct routes into single motherhood. A woman can become a single mother if the maximal level of utility that she can achieve by choosing the unmarried with children option exceeds expected utility in all the other possible states. Alternatively, a woman can become a divorced mother if she chooses to get married and have children, but then gets divorced.

The utility function, before making any assumptions about functional form, can be expressed as:

$$
U_{i s t}^{j}\left(c_{i s t}^{j}, l_{i s t}^{j}, k_{i s t}^{j}, m_{i s t}^{j}, x_{i s t}, \varepsilon_{i s t}^{j}\right) .
$$

Where $c$ is the consumption level, $l$ stands for leisure, $k$ indicates the presence of children, and $m$ stands for marriage ${ }^{8}$. Included in $x$ are relevant characteristics of the woman, such as her age and education level. Finally, the $\varepsilon^{\prime}$ s incorporate the heterogeneity across women in their taste for marriage and children.

The woman's consumption is determined by the level of income in the household, adjusted by the composition of the household:

$$
c_{i s t}^{j}=\frac{w_{i s t} h_{i s t}^{j}+B_{s t}^{j}+I_{i s t}^{j}}{g\left(m_{i s t}^{j}, k_{i s t}^{j}\right)}
$$

\footnotetext{
${ }^{7}$ In fact marriage dissolution can take place through separation, divorce or widowhood. I will refer to "divorce" in general for simplicity.

${ }^{8}$ In practice, cohabiting couples will also be included as married.
} 
Income is composed of the woman's labor earnings (wh), the benefits received by all members of the household $(B)$, and her partner's income $(I)$. The wage rate is assumed not to vary with $j$, while benefits are set at the country level and vary with family composition. The partner's income is zero if the woman remains single, and it includes child support or alimony payments if she’s divorced.

There is a time constraint, so that she needs to distribute her time between work, leisure, and childcare $\left(T=h_{i s t}^{j}+l_{i s t}^{j}+t_{i s t}^{j}\right)$, and children require a minimum amount of time that must be provided by the mother $(t>0$ if $k>0)$. She chooses marital status and fertility to maximize her utility, given the time and budget constraints.

The probability that a woman $i$ in country $s$ and period $t$ is a never married mother can thus be expressed as follows:

$$
P_{i s t}^{j=2}=P\left(U_{i s t}^{2} \geq U_{i s t}^{j}, \forall j \neq 2\right)
$$

If the woman chooses to get married and have children, then there is a certain probability $\left(\mu_{s t}\right)$ that the marriage will fail. Thus, the probability that a woman ends up divorced with children is:

$$
\mu_{\text {st }} P_{i s t}^{j=4}=\mu_{s t} P\left(U_{i s t}^{4} \geq U_{i s t}^{j}, \forall j \neq 4\right)
$$

The overall probability that a woman $i$ in country $s$ and period $t$ is a single mother equals the sum of the two components just described:

$$
P_{i s t}^{s m}=P_{i s t}^{j=2}+\mu_{s t} P_{i s t}^{j=4}=P\left(U_{i s t}^{2} \geq U_{i s t}^{j}, \forall j \neq 2\right)+\mu_{\text {st }} P\left(U_{i s t}^{4} \geq U_{i s t}^{j}, \forall j \neq 4\right)
$$

Note that although there is a direct choice to have children while unmarried, the woman does not choose divorce directly; she just chooses to get married and have children, in the awareness that the marriage will be dissolved with a certain probability, which may vary by country and over time. 
This simple model, under some weak assumptions about the functional form of the utilities, provides some predictions regarding the effect of the variables of interest on the incidence of single mothers. The first one is the level of public assistance. The higher the benefits available in any given state, e.g. never married mother with children, the higher the probability that a woman will choose that option. ${ }^{9}$ Both the absolute level of support and the eligibility rules (i.e. the level of support relative to other family types) are potentially relevant.

The model doesn't provide a clear prediction for the effect of the female wage level on the prevalence of single mothers. On the one hand, by raising her income, high wages would make it easier for a woman to live without a partner, lowering the gains from marriage through an income effect. Thus better economic opportunities could increase the probability of becoming a single mother. However, by raising the opportunity cost of a birth (in terms of foregone earnings, since children require time from the mother), high wages could discourage women from having children (substitution effect). Thus, from a theoretical point of view, the sign of the effect of female wages on the prevalence of single mothers is ambiguous. ${ }^{10}$

Finally, as mentioned, some studies attribute the increase in the prevalence of single mothers in the US to a reduced supply of marriageable men. Male employment and earnings enter the model through the woman’s budget constraint. Higher male earnings and better male employment prospects make marriage more attractive for women. ${ }^{11}$ Encouraging marriage may have a negative effect on the likelihood of choosing to be an unmarried mother. Higher male earnings would imply higher earnings in the household if the woman stays married, but also if she gets divorced (through alimony payments).

\footnotetext{
${ }^{9}$ More specifically, under the assumption that $U^{j}$ is (weakly) increasing in $B^{j}, \partial P^{j} / \partial B^{j} \geq 0$.

${ }^{10}$ The sign of this relationship will depend on the functional form of the utilities, and on expected hours of work across the different states.

${ }^{11}$ If utility is (weakly) increasing in partner's earnings $(I)$, then $\partial P^{j} / \partial I^{j} \geq 0$. Increases in male earnings increase $I$ only in the married states $(j=3$ and $j=4)$, since $I=0$ for single women.
} 
Thus higher male earnings make the married states more attractive, automatically increasing the number that end up in divorce. ${ }^{12}$

This model is of course extremely simplistic and it ignores important aspects such as the possibility of marriage for unmarried mothers and remarriage for divorced mothers, or the direct determinants of the divorce decision. However, the design was dictated largely by the cross-sectional nature of the available data. It is obviously not intended to provide an entirely realistic description of the way women make the fertility and marriage decisions, but rather to offer a framework that allows for an economic interpretation of the estimated parameters.

\subsection{Implementation}

In order to estimate the model, some assumptions need to be made about the functional form of the utilities, and about the distribution of the residuals. I assume a linear individual utility function, so that eq. (1) becomes:

$$
U_{i s t}^{j}=\alpha_{i s t}+\beta c_{i s t}^{j}+\gamma_{i s t}^{j}+\delta k_{i s t}^{j}+\eta m_{i s t}^{j}+\rho\left(m_{i s t}^{j} \cdot k_{i s t}^{j}\right)+\Gamma^{j} x_{i s t}+\varepsilon_{i s t}^{j} .
$$

Where, again, $c$ is the consumption level, $l$ stands for leisure, $k$ indicates the presence of children, $m$ stands for marriage, and the interaction term $m \cdot k$ accounts for the possibility that women value children within marriage above and beyond the separate preferences for marriage and children. We expect the coefficients for consumption, leisure, marriage and children to be positive. Included in $x$ are relevant individual characteristics of the woman, such as her age and education level.

The only complication derives from the fact that there is uncertainty regarding whether a marriage will be dissolved. Expected utility in the married states $(j=3$ and $j=4$ ) is thus a weighted average of the married and the divorced states. Letting $d$ denote

\footnotetext{
${ }^{12}$ For a given divorce probability.
} 
the divorced state, expected utility from choosing to get married and have children equals:

$$
\begin{aligned}
& U_{i s t}^{4}=\left(1-\mu_{s t}\right)\left[\alpha_{i s t}+\beta c_{i s t}^{4(d=0)}+\gamma_{i s t}^{4(d=0)}+\delta+\eta+\rho+\Gamma^{4(d=0)} x_{i s t}\right]+ \\
& \mu_{i s t}\left[\alpha_{i s t}+\beta c_{i s t}^{4(d=1)}+\gamma_{i s t}^{4(d=1)}+\delta+\Gamma^{4(d=1)} X_{i s t}\right]+\varepsilon_{i s t}^{4} .
\end{aligned}
$$

Leisure time is unobservable, so in practice it is taken to vary with country (s), year $(t)$, state $(j)$, and observable characteristics $(x)$. Thus the difference in leisure time across individuals and states will be captured by dummies that vary with country, year and state (possibly reflecting differences in childcare availability and informal childcare practices across countries), plus the $x$ 's.

Total income is adjusted by composition of the household through a fairly standard equivalence scale: (1+ 0.5 number of additional adults +0.3 number of children). ${ }^{13}$ The coefficient for consumption is allowed to vary with the source of income.

Under the additional assumption that the $\varepsilon_{\text {ist }}^{j}$ are distributed i.i.d. extreme value, we can estimate the probabilities $P_{\text {ist }}^{j}$ with a multinomial (conditional) Logit. The probability that a woman $i$ from country $s$ in period $t$ is a never married mother then equals:

$$
P_{i s t}^{j=2}=\frac{e^{\beta_{1} w_{i s t} h_{i s t}^{2}+\beta_{2} B_{s t}^{2}+\delta+\Gamma^{2} x_{i s t}+\varsigma_{s t}^{2}}}{\sum_{j} e^{\beta_{1} w_{i s t} h_{i s t}^{j}+\beta_{2} B_{s t}^{j}+\beta_{3} I_{i s t}^{j}+\delta k_{i s t}^{j}+\eta m_{i s t}^{j}+\rho\left(m_{i s t}^{j} k_{i s t}^{j}\right)+\Gamma^{j} x_{i s t}+\varsigma_{s t}^{j}}}
$$

Where $\varsigma_{s t}^{j}$ stands for the set of dummies that vary with country, year and state, ${ }^{14}$ and where the income variables have been adjusted by the composition of the household.

As for the probability that a woman is divorced with children,

\footnotetext{
${ }^{13}$ Alternative adjustment scales are also explored.

${ }^{14}$ Their exact definition is specified in section 5 .
} 


$$
\mu_{s t} P_{i s t}^{j=4}=\mu_{s t} \frac{e^{\beta\left[\left(1-\mu_{s t}\right) c_{i s t}^{4(d=0)}+\mu_{s t} c_{i s t}^{4(d=1)}\right]+\delta+\left(1-\mu_{s t}\right)(\eta+\rho)+\Gamma^{4} x_{i s t}+\varsigma_{s t}^{4}}}{\sum_{j} e^{\beta_{1} w_{i s t} h_{i s t}^{j}+\beta_{2} B_{s t}^{j}+\beta_{3} I_{i s t}^{j}+\delta k_{i s t}^{j}+\eta m_{i s t}^{j}+\rho\left(m_{i s t}^{j} k_{i s t}^{j}\right)+\Gamma^{j} x_{i s t}+\varsigma_{s t}}}
$$

Where consumption in the numerator has not been disaggregated into its three components for presentational simplicity.

The overall incidence of single mothers in a given country and period would just equal the sum of the incidence of never married and divorced mothers. The derivatives of this incidence with respect to the variables of interest can easily be calculated. If the coefficients on income (the $\beta^{\prime}$ s) are positive, the predicted effects are summarized in table 1. Increases in benefits for never married mothers are expected to increase the incidence of this type of households, and similarly, higher benefits for divorced mother are expected to lead to more families headed by a divorced mother. The effect of increasing benefits for all single mother families, however, would be positive on the incidence of never married mothers, but ambiguous for divorced mothers (and a function of the probability of divorce).

The predicted effect of female wages is ambiguous and depends on how hours of work vary across alternative states. Higher male earnings and employment rates are expected to reduce the incidence of never married mothers, while increasing the attractiveness of marriage, thus leading to a higher number of divorces.

\section{Data and Descriptive Evidence}

\subsection{The Luxembourg Income Study}

The Luxembourg Income Study database is a collection of household income surveys that includes 29 countries, with (cross-sectional) datasets that span up to three decades, 
organized in 5 waves, although not all countries have data sets for each of the waves. ${ }^{15}$ The advantage of this data source is that demographic and income variables are made easily comparable across data sets, which makes country comparisons feasible. The main disadvantage is that the data are not longitudinal and no information is provided about the timing of marriage and divorce. The nature of the data constrains considerably the type of model that we can estimate.

I keep all countries with at least two years of data available and sufficient information on marital status and earnings. I end up using LIS data sets for 14 countries, ${ }^{16}$ for five "waves" that correspond to the years 1984-87, 1988-91, 1992-95, 1996-99 and 2000-01. The five periods are available for just 2 countries, while only two waves are available for one country. The remaining 11 countries have 3 or 4 waves available. There are 50 country-year observations. ${ }^{17}$

The population of interest includes all women aged 18 to 55. The sample size is 383,397 observations. Most specifications will however focus on women aged 18 to 45, whose family formation decisions are more likely to be affected by current labor market conditions and benefit levels. The sample size for this younger population is 295,275.

\subsection{The Incidence of Single Mothers}

Never married mothers are defined as never married women who live by themselves with their children younger than 18. Divorced mothers are defined as divorced, separated or widowed women who live by themselves with their children younger than 18. Cohabiting mothers are counted as married.

\footnotetext{
${ }^{15}$ Information on the LIS database is available online at www.lisproject.org.

${ }^{16}$ Australia, Austria, Belgium, Canada, Finland, Hungary, Ireland, Israel, Italy, Luxembourg, Netherlands, the United Kingdom and the United States.

${ }^{17}$ See table A.1 in the appendix for a list of the years used for each country.
} 
Figure 2 shows the number of single (never married or divorced) mothers in each of the 14 countries, as a proportion of all women aged 18 to 55, by year. In the late 1990's, the United Kingdom and the United States experienced the highest incidence of single mothers (between 7 and 9 percent of all women). The lowest incidence was observed in Italy and Hungary, with less than 2 percent. The evolution of the prevalence of single mother households over time was also quite different across the 14 countries. Israel, Germany, Ireland or Canada experience substantial increases during the 1980's and 1990’s, while a considerable decline was observed in Hungary or The Netherlands.

We would like to understand how much of the cross-country variation in the incidence of single mothers, as well as its change over time, can be attributed to differences in the number of never married versus divorced mothers. Figure 3 displays the proportion of never married and divorced mothers separately, by country, in (approx.) 1993. Divorced mothers were more numerous than never married mothers in all countries but Ireland. However, the number of never mothers increased during the two decades in all countries but Hungary, while the number of divorced mothers experienced a slower growth, and it actually fell in five countries. On average, during the 1980's and 1990's the number of never married mothers more than doubled, while there was a 19 percent increase in the incidence of divorced mothers.

Thus, there is substantial variation across countries in the overall incidence of single mothers, as well as by marital status. The evolution over time also differs considerably. Divorced mothers were more frequent in practically all countries in the early 1990's, but the number of never married mothers increased much more rapidly between 1980 and 2000. In 1992-95, the cross-country correlation between the proportion of divorced and never married mothers was .67. The correlation between the changes in both components over time across countries is .49. 
Both components contribute to the cross-country variation in the prevalence of single mothers. The correlation between the overall incidence and the number of never married mothers in 1992-95 was .89, while the correlation with the number of divorced mothers was .93. An alternative measure of how much of the overall variation in the prevalence of single mothers can be attributed to each group is the covariance between the overall prevalence and each component, divided by the variance in the overall prevalence of single mothers. The advantage of this measure over the raw correlations is that it accounts for the magnitude of the contribution of each component to the overall variance in the prevalence of single mothers, as well as for the closeness of fit. According to this measure, the prevalence of divorced mothers contributes 57 percent to the overall variance, while the prevalence of never married mothers accounts for the remaining 43 percent of the variance in the overall prevalence of single mothers.

When analyzing the changes over time, the results are similar. The changes in the incidence of divorced mothers contribute 65 percent to the variance in the change of the total number of single mothers, while changes in never married mothers account for the remaining 35 percent.

Therefore, it appears that the variation in the prevalence of single mothers, both across countries and over time, can be attributed to differences in both out-of-wedlock fertility and divorce. Moreover, the incidence of never married and divorced mothers follow different paths across countries and over time, which points to the usefulness of a model that examines their determinants separately, versus the usual approach of lumping both groups of women into a single "female heads" category. 


\section{Estimation Results}

\subsection{Variables and Summary Statistics}

The model is estimated using individual-level data for 14 countries in 5 periods (there are 50 country-period observations). The sample includes all women aged 18 to 45 . The variables of interest are benefit levels, female wages, and male variables (earnings and employment levels, as well as child support payments). The following conditional logit model (as introduced in section 3) for the determinants of single motherhood for person $i$, in country $s$ and period $t$ is estimated:

$$
P_{i s t}^{j}=\frac{e^{\beta_{1} w_{i s t} h_{i s t}^{j}+\beta_{2} B_{s t}^{j}+\beta_{3} I_{i s t}^{j}+\delta k_{i s t}^{j}+\eta m_{i s t}^{j}+\rho\left(m_{i s t}^{j} k_{i s t}^{j}\right)+\Gamma^{j} x_{i s t}+\varsigma_{s t}^{j}}}{\sum_{q=1}^{4} e^{\beta_{1} w_{i s t} h_{i s t}^{q}+\beta_{2} B_{s t}^{q}+\beta_{3} I_{i s t}^{q}+\delta k_{i s t}^{q}+\eta m_{i s t}^{q}+\rho\left(m_{i s t}^{q} k_{i s t}^{q}\right)+\Gamma^{q} x_{i s t}+\varsigma_{s t}^{q}}}
$$

A woman is thus assumed to choose marital status and fertility in order to maximize her utility, using her expectations about her own wage, hours of work, benefits, and husband's earnings.

Expected hourly wage for women in a given country and period is calculated as the average wage of all employed women, by age and education (see appendix for details on the LIS variables used). In order to address selection issues derived from low employment rates in certain subpopulations, an alternative measure of expected wage is calculated using only unmarried women without children. Hours of work are calculated as the average number of hours that women work per year (in country $s$ and period $t$ ). Hours are allowed to vary with $j$ since we assumed that children require time from the mother. On average, mothers work fewer hours than non-mothers in all countries. ${ }^{18}$ Table 2 shows average hourly wage for women aged 18 to 45 with a high school degree

\footnotetext{
${ }^{18}$ On average, women without children aged 18 to 55 work 1,061 hours a year, versus 838 hours for women with children.
} 
and no university education by country, in period 3 (1992-95). The lowest wages were paid in Hungary, while female hourly wage is highest in Luxembourg and Germany.

Expected benefits are also a function of household composition, and reflect the changing benefit schedules at the country level. Thus benefits are calculated as the average received by each household type in a given country and period. I include family-related benefits, such as child and family allowances or single parent benefits, and social assistance, including means-tested transfers and near-cash benefits like food stamps or childcare subsidies (see appendix). Table 2 shows average benefit levels received by single mother families by country in 1992-95. Benefits were very low in Italy, while they were highest in The Netherlands and the UK.

Expected husband's earnings are calculated as average earnings for employed men, times the male employment rate. They are allowed to vary with age and education level, since marriage market conditions may vary by cohort and with education. Table 2 shows average earnings for employed men with a high school degree and no college and ages between 20 and 47, by country, in 1992-95. Male earnings are very low in Hungary, while the highest levels correspond to Canada and Luxembourg.

Child support payments are calculated as average payments received by divorced women in a given country and period. They are allowed to vary with children and education level.

Age and education level are included in the model separately since they may affect a woman's preferences for marital status and children directly. I define three education levels, which correspond approximately to less than a high school degree, high school graduates, and college graduates (see appendix for details). Age is included as a dummy for women aged 30 or younger. The coefficients on age and education are allowed to vary with $j$. 
Finally, a set of dummies for country and period, interacted with $j$, are included. Three different sets of dummies are used in alternative specifications: country dummies and period dummies, country dummies and time trends, and country dummies interacted with time trends. Thus in practice we are controlling for unobservable factors that may affect family formation and that are fixed at the country level or changing at the same pace in all countries. In the specifications with country-specific time trends, we are also allowing for unobserved time-varying factors at the country level.

All monetary variables are normalized using Purchasing Power Parities. ${ }^{19}$ They are also adjusted by household composition. Table 3 shows some descriptive statistics for the sample of women aged 18 to 45 . About 50 percent are ever married with children, while only 2.35 percent are never married with children. Almost 52 percent of the women in the sample have a high school degree (but no college), while 22 percent have a university education. About 43 percent are 30 years old or younger. Average female wage is 9 dollars an hour, and women work on average 1,059 hours a year. Average male earnings are 24,000 dollars a year, and their average employment rate is 80 percent. Divorced women with children receive on average 1,737 dollars a year in child support and/or alimony payments. Average benefits received by a household amount to almost 1,600 dollars a year.

\subsection{Results}

Table 4 presents the coefficients from several specifications of the conditional logit model. The estimated coefficients for female wages, benefits and husband's earnings are positive (as expected, since individuals are assumed to derive utility from consumption) and significant in most specifications, except for benefits. The

\footnotetext{
${ }^{19}$ Provided by the OECD, in current US dollars.
} 
coefficients on marriage and children ${ }^{20}$ indicate that the least preferred family status is never married motherhood, while the most preferred states seem to be single without children and married with children (not significantly different from each other). Higher educational attainment is significantly associated with a lower likelihood of having children (both single and married). Younger women are more likely to be single and childless, and as they age they become more likely to be never married mothers, married without children, and married with children, successively. Finally, most of the country and time dummies are significant. Recall that these dummies are in practice controlling for unobserved variables at the country level that may affect marital status and fertility, and that these country effects are allowed to vary over time in the specifications where the country dummies are interacted with the time trends.

Table 5 displays the marginal effects associated with changes in each of the explanatory variables. They are calculated as the average of the derivatives at the value of the explanatory variables for each observation, and the standard errors are calculated using the delta method. Increases in the level of benefits that single mother families receive seem to be significantly associated with a higher prevalence of both never married and divorced mothers. A 10 percent increase in benefits for single mother families (leaving benefits for all other households unchanged) would result in a 5 percent increase in the incidence of single mothers (note that the average incidence of single mothers is 6.6 percent of all women 18 to 45 ).

A potential problem with this result is raised by concerns about the exogeneity of benefit levels. If increases in the prevalence of single mothers in a given country trigger increases in public assistance for this family type, this would generate positive estimated effects despite the reverse causality. However, I found no evidence that this

\footnotetext{
${ }^{20}$ Not shown in the table.
} 
was the case in any of the countries under consideration. If anything, the countries that experienced large increases in the prevalence of single mothers tended to implement reforms that reduced the benefits available to these families, reforms motivated by concerns that high benefit levels were encouraging single motherhood. Note that if this is the case, then the results that I report might be underestimating the true effects of benefits.

Higher male earnings and male employment rates appear to lead to significant declines in the incidence of never married mothers, while increasing the number of divorced mothers significantly. A 10 percent increase in male earnings would result in a 5.8 percent decrease in the number of never married mothers, while increasing the incidence of divorced mothers by about 3.4 percent. The overall effect on the prevalence of single mothers is negative but small and not significant. Higher child support payments are significantly associated with more divorced mothers, although the effect is small (and with fewer never married ones, although the overall effect is significantly positive).

Finally, higher female hourly wages seem to be associated with a significantly lower prevalence of never married mothers. The estimated effect is also negative (but only marginally significant) for divorced mothers. Thus it appears that the substitution effect through reduced hours of work associated with motherhood would dominate the income effect. A 10 percent increase in female hourly wages is estimated to result in a 3.4 percent decline in the incidence of single mothers.

Note, however, that there is no single effect of marriage market and labor market conditions on the prevalence of single mothers. The effect of male earnings and employment rates, for instance, varies for never married versus divorced mothers, but it is also heterogeneous across marriage markets, and even within marriage markets, 
depending on the relative position of individual women. The heterogeneity across marriage markets can be highlighted by looking at the distribution of the marginal effects across women in different marriage markets. For never married motherhood, the average effect of male earnings is -.061 (see table 4). However, the median effect is .053 , with the $10^{\text {th }}$ percentile at -.111 and the $90^{\text {th }}$ at -.007 . As for the effect on the incidence of divorced mothers, an average effect of .058 is actually distributed with a $10^{\text {th }}$ percentile at .026 and a $90^{\text {th }}$ percentile of .107.

Also informative is the distribution of the marginal effects of female wage levels on the incidence of single mothers. While the average derivative is significantly negative at -.244 , the effects vary across women, with a $10^{\text {th }}$ percentile at -.498 and a $90^{\text {th }}$ percentile that is in fact positive, at .029.

The structural nature of the model allows for simulations of different scenarios. We can for instance analyze the predicted effects of different changes in the benefits schedules. It may be interesting to compare the effects of increases in benefits that are targeted to single mother families, versus increases in universal family benefits, common in some European countries. The results indicate that increasing benefits for all families with children (including both single and married mothers) would still result in significant increases in the number of single mothers (see table 4). The increase in never married mothers would be smaller than in the case of targeted benefits, but the incidence of divorced mothers would rise even more than with targeted benefits (since both the married and the divorced states are made more attractive, thus leading to large increases in marriage with children, and consequently more divorces).

We can also simulate different scenarios by country. For instance, in the US never married mothers received on average $\$ 3,780$ in public assistance in 2000. The model predicts that, were benefits for never married mothers cut by a half, the incidence of 
these households would fall by 3.3 percent. If, instead, male earnings were to increase by $50 \%$, the number of never married mothers would fall by 2.2 percent.

The results can help us understand some of the trends observed in the data. As can be seen in figure 2 (and as described in section 4.2), Hungary and The Netherlands experienced the most significant declines in the incidence of single mothers, while large increases took place in Canada, Ireland, the UK and Germany. As it turns out, both Hungary and The Netherlands suffered nominal cuts in benefit levels for single mother families during the period. In fact, average benefits received by Dutch single mothers fell by $17 \%$ in nominal terms during the 1990's (from 7,900 in 1991 to 6,600 in 1999, in current US\$). At the same time, Canada, the UK and Germany experienced substantial increases in public assistance for single mother families. The average single mother in the UK received \$7,800 in 1991, compared with \$11,500 in 1999.

\subsection{Alternative Specifications and Robustness Checks}

The results seem robust to a number of different specifications and robustness checks. Alternative specifications are estimated using different age cuts for the sample of women. When including women 18 to 55, the signs of the coefficients and average derivatives remain unchanged, but they become less significant. The results are also robust to different adjustments for household composition.

As a robustness check, I estimate the same set of regressions with a different scaling for monetary variables. Instead of Purchasing Power Parities, I normalize earnings and benefits using per capita income in a given country and period. The results are quite similar. 
The baseline regressions are re-estimated imposing a common coefficient for all the components of consumption, with no significant changes in the main results. Specifications are also run with period dummies instead of time trends.

In order to ascertain how much the results are being driven by the US, I estimate the model excluding the US data. It turns out that, although the signs of the effects remain unchanged, the sizes of the coefficients for the income variables and their significance levels are increased. In particular, the coefficient for benefit levels is now always significant, while it was not in the specifications that included the US (see table 4).

Objections could be posed to the use of a multinomial logit for estimation of the model. Although many have noted that fertility and marriage decisions are made jointly, ${ }^{21}$ a nested structure may seem more appealing. We could think of the decision process as that of choosing whether to get married or not, and then making the fertility decision within the chosen marital status. This approach would relax the assumption of independence from irrelevant alternatives (IIA) implicit in the multinomial logit model. Thus I estimate nested logit models with two alternative nesting structures in order to compare the results with the baseline multinomial model. ${ }^{22}$ The signs of the coefficients are unchanged and the magnitudes and significance levels are similar. The main results for the income variables seem robust to the nesting structure.

Finally, I estimate the model including only observations for women with no college education. As expected, the estimated effects of public assistance are larger and more significant than for the full sample. The coefficients for female wage and marriage market conditions also appear to increase slightly in magnitude.

\footnotetext{
${ }^{21}$ See Montgomery and Trussell 1986.

${ }^{22}$ The first nesting structure has one branch for single and one for married states, while the second structure has one branch for childless states and one for states with children.
} 


\section{Summary and Conclusions}

The goal of this paper was to exploit the variation across countries and over time to shed light on the determinants of the incidence of single motherhood. The results suggest that benefit systems, labor market and marriage market conditions do influence marriage and fertility decisions, and thus the likelihood that a woman is a single mother in a given country and period.

With individual-level data for 14 countries for the 1980's and 1990's, I examine the effect of three groups of economic variables on the prevalence of single mothers. These include the level of public support, female wage levels, and marriage market conditions as measured by male earnings and employment levels. Although these factors can account for only part of the cross-country variation, they do appear to be significantly associated with the incidence of single mothers, and the effects are largely consistent with the predictions of the model.

The results indicate that a $10 \%$ increase in (yearly) benefits for single mothers, leaving benefits unchanged for other families, would increase the prevalence of single mothers by about 5 percent. A 10\% increase in female hourly wage would lower the average prevalence of single mothers by 3 percent. A higher prevalence of never married mothers is also associated with lower male earnings and employment rates in a woman's marriage market. A $10 \%$ increase in average male yearly earnings would decrease the prevalence of never married mothers by 6 percent, on average, while the effect on the prevalence of divorced mothers is positive and significant. The overall effect of male earnings and employment levels on the incidence of single mothers is negative but insignificant. Finally, increases in child support or alimony payments are associated with a higher prevalence of divorced mothers, although the estimated effects are very small. 
The results thus suggest that never married and divorced mothers are influenced differently by economic variables. Never married mothers appear to be more frequent in environments where female wages are low, marriage market conditions are poor (male earnings and employment rates are low), and social assistance generous and targeted. As for divorced mothers, their incidence seems higher in settings where male earnings and employment rates are high, public support for families with children is more generous, and child support and alimony payments high. 


\section{References}

Akerlof, G. A., J. L. Yellen and M. L. Katz. 1996. “An Analysis of Out-Of-Wedlock Childbearing in the United States.” Quarterly Journal of Economics 111(2): 277-317.

Angrist, J. 2002. "How Do Sex Ratios Affect Marriage and Labor Markets? Evidence from America's Second Generation.” Quarterly Journal of Economics 117(3): 997-1038.

Becker, G. S. 1960. "An Economic Analysis of Fertility." In Demographic and Economic Change in Developed Countries. Princeton, NJ: Princeton University Press.

Becker, G. S. 1973. "A Theory of Marriage: Part I." Journal of Political Economy 81(4): 813-846.

Becker, G. S. 1974. "A Theory of Marriage: Part II." Journal of Political Economy 82(2): S11-S26.

Becker, G. S. and R. J. Barro. 1988. "A Reformulation of the Economic Theory of Fertility.” Quarterly Journal of Economics 103(1): 1-25.

Becker, G. S., E. M. Landes and Robert T. Michael. 1977. "An Economic Analysis of Marital Instability." Journal of Political Economy 85(6): 1141-1188.

Blau, F., L. Kahn and J. Waldfogel. 2004. "The Impact of Welfare Benefits on Single Motherhood and Headship of Young Women. Evidence from the Census.” Journal of Human Resources 39(2): 382-404.

Bradshaw, J. 1998. "International Comparisons of Support for Lone Parents." In Private Lives \& Public Responses. Lone parenthood \& future policy in the UK, 154-168. London: Policy Studies Institute.

Brien, M. 1997. "Racial Differences in Marriage and the Role of Marriage Markets." Journal of Human Resources 32: 741-778.

Danziger, S., G. Jakubson, S. Schwartz and E. Smolensky. 1982. "Work and Welfare as Determinants of Female Poverty and Household Headship.” Quarterly Journal of Economics 97: 519-534.

Duncan, G. and S. Hoffman. 1990. "Welfare Benefits, Economic Opportunities and the Incidence of Out-of-Wedlock Births Among Black Teenage Girls." Demography 27(4): 519-535.

Edlund, L. 2005. "The Role of Paternity Presumption and Custodial Rights for Understanding Marriage Patterns.” Unpublished draft. Columbia University.

Ellwood, D. and M. J. Bane. 1985. "The Impact of AFDC on Family Structure and Living Arrangements.” Research in Labor Economics 7: 137-207. 
Fitzgerald, J. 1991. "Welfare Durations and the Marriage Market: Evidence from the Survey of Income and Program Participation.” Journal of Human Resources 26(3): 545-61.

Hoffman, S. and G. Duncan. 1988. "A Comparison of Choice-Based Multinomial and Nested Logit Models: The Familiy Structure and Welfare Use Decisions of Divorced or Separated Women." Journal of Human Resources 23: 550-562.

Hoynes, H. W. 1997. "Does Welfare Play Any Role in Female Headship Decisions?", Journal of Public Economics 65: 89-118.

Jackson, C. A. and Jacob A. Klerman 1996. “Welfare and American Fertility.” RAND Working Paper.

Krein, S. F. and A. H. Beller. 1988. "Educational Attainment of Children From SingleParent Families: Differences by Exposure, Gender, and Race.” Demography 25(2): 221-234.

Lerman, R. 1996. "The Impact of the Changing US Family Structure on Child Poverty and Income Inequality” Economica 63(250): S119-39.

Lichter, D. T., D. K. McLaughlin and D. C. Ribar. 1997. "Welfare and the Rise in Female-Headed Families” American Journal of Sociology 103(1): 112-43.

Lundberg, S. and R. D. Plotnick. 1995. “Adolescent Premarital Childbearing: Do Economic Incentives Matter?” Journal of Labor Economics 13: 177-200.

Luxembourg Income Study (LIS) Microdatabase. 2005. Harmonization of original surveys conducted by the Luxembourg Income Study, asbl. Luxembourg, periodic updating.

McLanahan, S. 1994. "The Consequences of Single Motherhood", American Prospect 18: 48-58.

McLanahan, S. and G. Sandefur. 1994. Growing up with a single parent: what hurts, what helps. Cambridge, Mass.: Harvard University Press.

Moffitt, R. 1990. "The Effect of the US Welfare System on Marital Status." Journal of Public Economics 41(1): 101-124.

Moffitt, R. 1992. "Incentive Effects of the US Welfare System: A Review." Journal of Economic Literature 30(1): 1-61.

Moffitt, R. 1994. "Welfare Effects on Female Headship with Area Effects." Journal of Human Resources 29: 621-636.

Moffitt, R. 1995. "The Effect of the Welfare System on Nonmarital Childbearing." In Report to Congress on Out-of Wedlock Childbearing. National Center for Health Statistics 95-1257-1. Hyattsville, Md.: Public Health Service. 
Moffitt, R. 1998. "The Effect of Welfare on Marriage and Fertility.” In Welfare, the Family, and Reproductive Behavior, ed. R. Moffitt. Washington: National Academy Press.

Moffitt, R. 2001. “Welfare Benefits and Female Headship in U.S. Time Series”. In Outof-Wedlock: Causes and Consequences of Nonmarital Fertility, eds. L. Wu and B. Wolfe. Russell Sage Foundation.

Montgomery, M. and J. Trussell. 1986. "Models of Marital Status and Childbearing." In Handbook of Labor Economics, ed. O. Ashenfelter and D. Card, 205-271. Amsterdam: North Holland.

Murray, C. 1984. Losing Ground - American Social Policy, 1950-1980. New York: Basic Books.

Neal, D. 2004. "The Relationship Between Marriage Market Prospects and NeverMarried Motherhood." Journal of Human Resources 39(4): 938-957.

Oppenheimer, V. K. 1994. "Women's Rising Employment and the Future of the Family in Industrial Societies.” Population and Development Review 20: 293-342.

Rich, L. M. and S. Kim. 2002. "Employment and the Sexual and Reproductive Behavior of Female Adolescents." Perspectives on Sexual and Reproductive Health 34(3): 127-134.

Rosenzweig, M. R. 1999. "Welfare, Marital Prospects, and Nonmarital Childbearing." The Journal of Political Economy 107(6): S3-S32.

Sander, W. 1985. "Women, Work, and Divorce." The American Economic Review 75(3): 519-523.

Schmidt, L. 2003. "Murphy Brown Revisited: Human Capital, Search and Nonmarital Childbearing Among Educated Women.” Unpublished draft. Williams College.

Schultz, P. T. 1994. "Marital Status and Fertility in the United States. Welfare and Labor Market Effects." The Journal of Human Resources 29: 637-669.

United States Census Bureau. 2001. (http://www.census.gov/main/www/cen2000.html).

Wallace, G. 2000. "An Assessment of Several Explanations for the Decline in Female Marriage Rates.” Unpublished draft. University of Wisconsin.

Whiteford, P. and J. Bradshaw. 1994. "Benefits and Incentives for Lone Parents: A Comparative Analysis." International Social Security Review 47(3/4): 69-89.

Willis, R. J. 1999. "A Theory of Out-Of-Wedlock Childbearing." Journal of Political Economy 107(6): S33-S64.

Wilson, W. J. 1987. The Truly Disadvantaged. Chicago: University of Chicago Press. 


\section{Data Appendix}

The analysis includes data for 14 countries and 5 periods. Periods were chosen for each country so that the data always come from the same national survey. ${ }^{23}$ Table A. 1 lists all countries and periods.

\section{Education}

Two education dummies are used in the analysis. They denote the highest educational level attained by an individual. One of the dummies indicates "upper secondary education and post-secondary non-tertiary education”, and a second dummy designates "tertiary education". In order to make these variables as comparable as possible across countries, I have followed the indications provided by LIS (see http://www.lisproject.org/dataccess/educlevel/educdefcountry.htm). To guarantee a sufficient level of international comparability, the proposed recoding follows the education classification of UNESCO, the ISCED-97.

\section{Wages and Earnings}

The following variables are used to calculate female hourly wage:

PNWAGE: Net wage and salary income.

PGWAGE: Gross wage and salary income.

PYTAX: Income taxes.

PMEEC: Mandatory employee contributions.

PHOURS: Number of hours worked per week.

PWEEKFT: Number of weeks worked/year full time.

PWEEKPT: Number of weeks worked/year part time.

When all variables were available, hourly wage was calculated as:

PNWAGE/(PHOURS*(PWEEKFT+PWEEKPT))

When net wage was not available, I used gross wage minus income taxes and employee contributions. When hours worked per week were not available, I used 40 hours for fulltime weeks and 20 hours for part-time weeks. When number of weeks worked was not available, I used 48 to 50 weeks, depending on guaranteed vacation time by country. The definition was kept unchanged in all periods for each country.

Average wage is calculated by education level (three different levels, see above) and by age group (18 to 30,31 to 45 , 46 to 55 ).

Male earnings are calculated as net wages when available, or gross wage minus income taxes and employee contributions. They are also estimated by education level and age group, although the age groups are slightly modified given that women tend to marry slightly older men (the age groups are 20 to 32, 33 to 47, and 48 to 57).

\section{Employment and Hours}

Male employment rates are calculated by education and age groups, and a man is classified as employed if he reports positive earnings, as defined above.

\footnotetext{
${ }^{23}$ Except for the UK: the data for 1991 and 1995 come from the Family Expenditure Survey, while the data for 1999 are from the Family Resources Survey.
} 
Female hours of work are calculated as average hours worked a year by women of a given family status, country and year. Hours worked per year were calculated as hours worked per week, times weeks worked per year (full time or part time). When hours worked per week were not available, I used 40 hours for full-time weeks and 20 hours for part-time weeks. When number of weeks worked was not available, I used 48 to 50 weeks, depending guaranteed vacation time by country. The definition was kept unchanged in all periods for each country.

\section{Benefits}

Benefits are calculated as average transfers received by a type of household (unmarried, married or divorced women, with or without children) during the year, by country and period. Benefits include social assistance (including means-tested benefits and near-cash benefits, such as food stamps or child care subsidies) and family-related benefits (including family and child allowances and single-parent benefits). The LIS variables used are V20, V22, V24, V25 and V26.

\section{Child support}

Child support (and/or alimony payments) received by divorced women with children are calculated using the LIS variable V34 (“Alimony and child support”) and, for coutries where this one was not available, V35 (“Other regular private income”).

Table A.1. LIS Datasets Used

\begin{tabular}{|l|c|c|c|c|c|}
\hline & $\mathbf{1 9 8 4 - 8 7}$ & $\mathbf{1 9 8 8 - 9 1}$ & $\mathbf{1 9 9 2 - 9 5}$ & $\mathbf{1 9 9 6 - 9 9}$ & $\mathbf{2 0 0 0 - 0 1}$ \\
\hline Australia & 1985 & 1989 & 1994 & & \\
\hline Austria & & & 1994 & 1997 & \\
\hline Belgium & 1985 & 1988 & 1992 & 1997 & \\
\hline Canada & 1987 & 1991 & 1994 & 1997 & \\
\hline Finland & 1987 & & 1995 & & 2000 \\
\hline Germany & 1984 & 1989 & 1994 & & 2000 \\
\hline Hungary & & 1991 & 1994 & 1999 & \\
\hline Ireland & & & 1994 & 1996 & 2000 \\
\hline Israel & 1986 & & 1992 & 1997 & 2001 \\
\hline Italy & & 1991 & 1995 & 1998 & 2000 \\
\hline Luxembourg & 1985 & 1991 & 1994 & 1997 & 2000 \\
\hline Netherlands & & 1991 & 1994 & 1999 & \\
\hline United Kingdom & & 1991 & 1995 & 1999 & \\
\hline United States & 1986 & 1991 & 1994 & 1997 & 2000 \\
\hline
\end{tabular}


Figure 1. Tree of Potential Outcomes

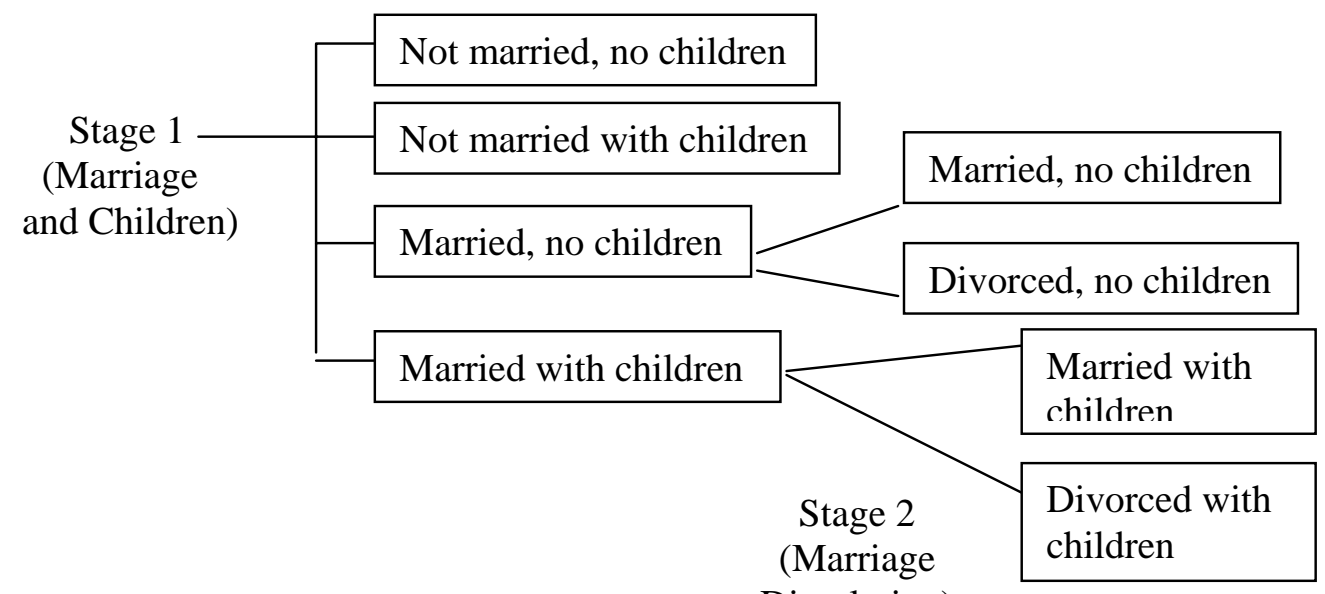

Dissolution)

Figure 2. Single Mothers as a Proportion of All Women 18 to 55

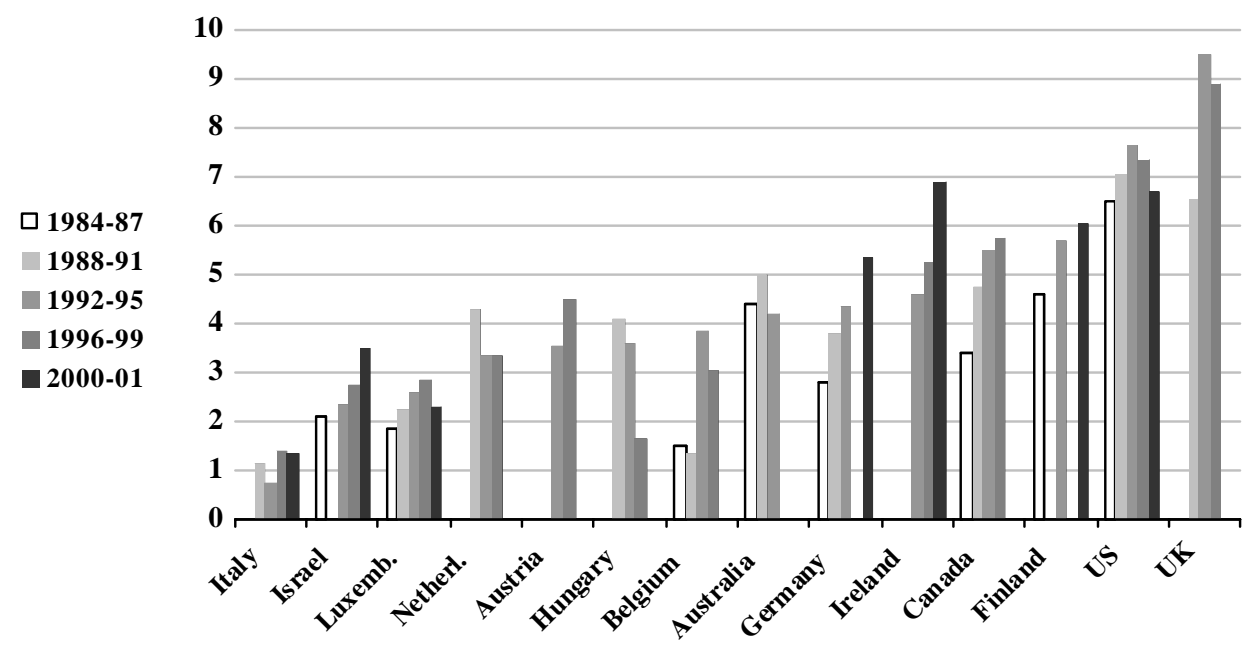

Note: LIS data, 14 countries included. Household weights have been used. Single mothers are defined as women aged between 18 and 55, living by themselves with their own children under the age of 18. 
Figure 3. Never Married and Divorced as a Proportion of All Women 18 to 55, 1992-1995.

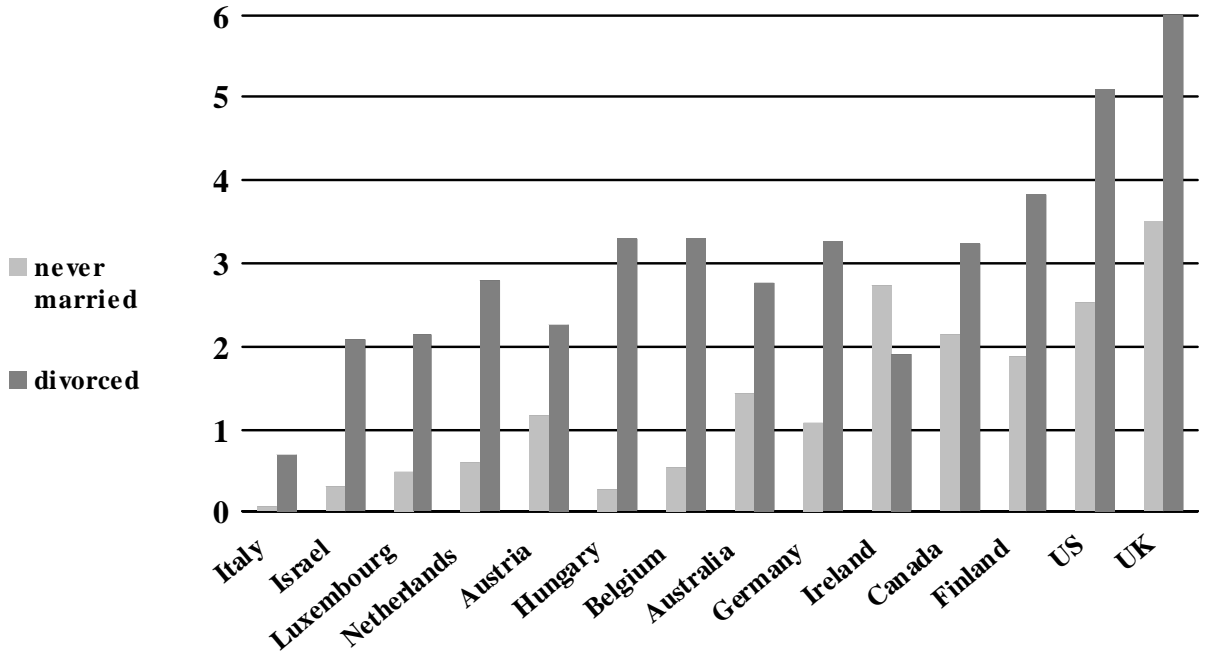

Note: LIS data, 14 countries included. Household weights have been used. Never married mothers are defined as never married women aged between 18 and 55, living by themselves with their own children under the age of 18 . Divorced mothers are defined as divorced, separated or widowed women aged between 18 and 55, living by themselves with their own children under the age of 18.

Table 1. Summary of Predicted Effects on the Prevalence of Single Mothers

\begin{tabular}{|l|c|c|c|}
\hline & $\begin{array}{c}\text { Never Married } \\
\text { Mothers }\end{array}$ & $\begin{array}{c}\text { Divorced } \\
\text { Mothers }\end{array}$ & $\begin{array}{c}\text { All Single } \\
\text { Mothers }\end{array}$ \\
\hline $\begin{array}{l}\text { Public Assistance } \\
\text { Single Mothers }\end{array}$ & + & $?$ & $?$ \\
\hline Female Wage Levels & $?$ & $?$ & $?$ \\
\hline $\begin{array}{l}\text { Male Earnings and } \\
\text { Employment }\end{array}$ & - & + & $?$ \\
\hline
\end{tabular}


Table 2. Average female wages, public transfers to single mothers, and male earnings, across 14 countries in the mid-1990's.

\begin{tabular}{lccc}
\hline & $\begin{array}{c}\text { Average female } \\
\text { wage }\end{array}$ & $\begin{array}{c}\text { Average transfers } \\
\text { single mother } \\
\text { families }\end{array}$ & $\begin{array}{c}\text { Average male } \\
\text { earnings }\end{array}$ \\
\hline Australia & 8.46 & 6,438 & 19,082 \\
Austria & 6.70 & 5,112 & 17,496 \\
Belgium & 6.40 & 3,293 & 15,229 \\
Canada & 9.95 & 5,963 & 25,225 \\
Finland & 5.64 & 5,820 & 11,411 \\
Germany & 10.89 & 3,012 & 18,818 \\
Hungary & 2.38 & 1,666 & 6,088 \\
Ireland & 6.49 & 6,673 & 16,140 \\
Israel & 5.87 & 1,955 & 18,790 \\
Italy & 7.26 & 74 & 15,411 \\
Luxembourg & 10.69 & 4,597 & 25,601 \\
Netherlands & 10.33 & 9,561 & 21,825 \\
United Kingdom & 9.54 & 8,751 & 20,595 \\
United States & 8.43 & 3,549 & 23,539 \\
\hline
\end{tabular}

Note: LIS data, amounts expressed in current PPP US \$, period 3 (1992-95). “Average female wage" is calculated for women aged 18 to 45 , with a high school degree but no university education. "Average male earnings" are calculated for men aged 20 to 47, with a high school degree ad no university education. 
Table 3. Summary Statistics

\begin{tabular}{lrrrr}
\hline Variable & Mean & Std. Dev. & Min & \multicolumn{2}{r}{ Max } \\
\hline $\begin{array}{l}\text { Never married w/o } \\
\text { children (j=1) }\end{array}$ & 0.2636 & 0.2084 & 0 & 1 \\
$\begin{array}{l}\text { Never married } \\
\text { with children (j=2) }\end{array}$ & 0.0235 & 0.0234 & 0 & 1 \\
$\begin{array}{l}\text { Ever married w/o } \\
\text { children (j=3) }\end{array}$ & 0.2138 & 0.0723 & 0 & 1 \\
$\begin{array}{l}\text { Ever married with } \\
\text { children (j=4) }\end{array}$ & 0.4990 & 0.2013 & 0 & 1 \\
High school & & & & \\
diploma & 0.5186 & 0.4997 & 0 & 1 \\
College & 0.2162 & 0.4116 & 0 & 1 \\
Young (<30) & 0.4317 & 0.4953 & 0 & 1 \\
Female wage & 8.9576 & 3.2353 & 1.5324 & 18.6287 \\
Female wage (2) & 9.0928 & 3.4212 & 0.9512 & 18.8116 \\
Male earnings & 23999 & 11394 & 3209 & 63731 \\
Male employment & 0.8026 & 0.1187 & 0.3208 & 0.9823 \\
Child support & 1737 & 938 & 263 & 4678 \\
Divorce & 0.1406 & 0.0455 & 0.0608 & 0.2169 \\
Fem. Hours & & & & \\
worked & 1059 & 218 & 105 & 1430 \\
Benefits & 1595 & 1347 & 0 & 11621 \\
\hline
\end{tabular}

Note: The sample consists of all women 18 to 45 years old. The data are pooled for all 14 countries in the 5 periods. Sample size is 295,254. 
Table 4. Conditional Logit Results for the Incidence of Single Mothers

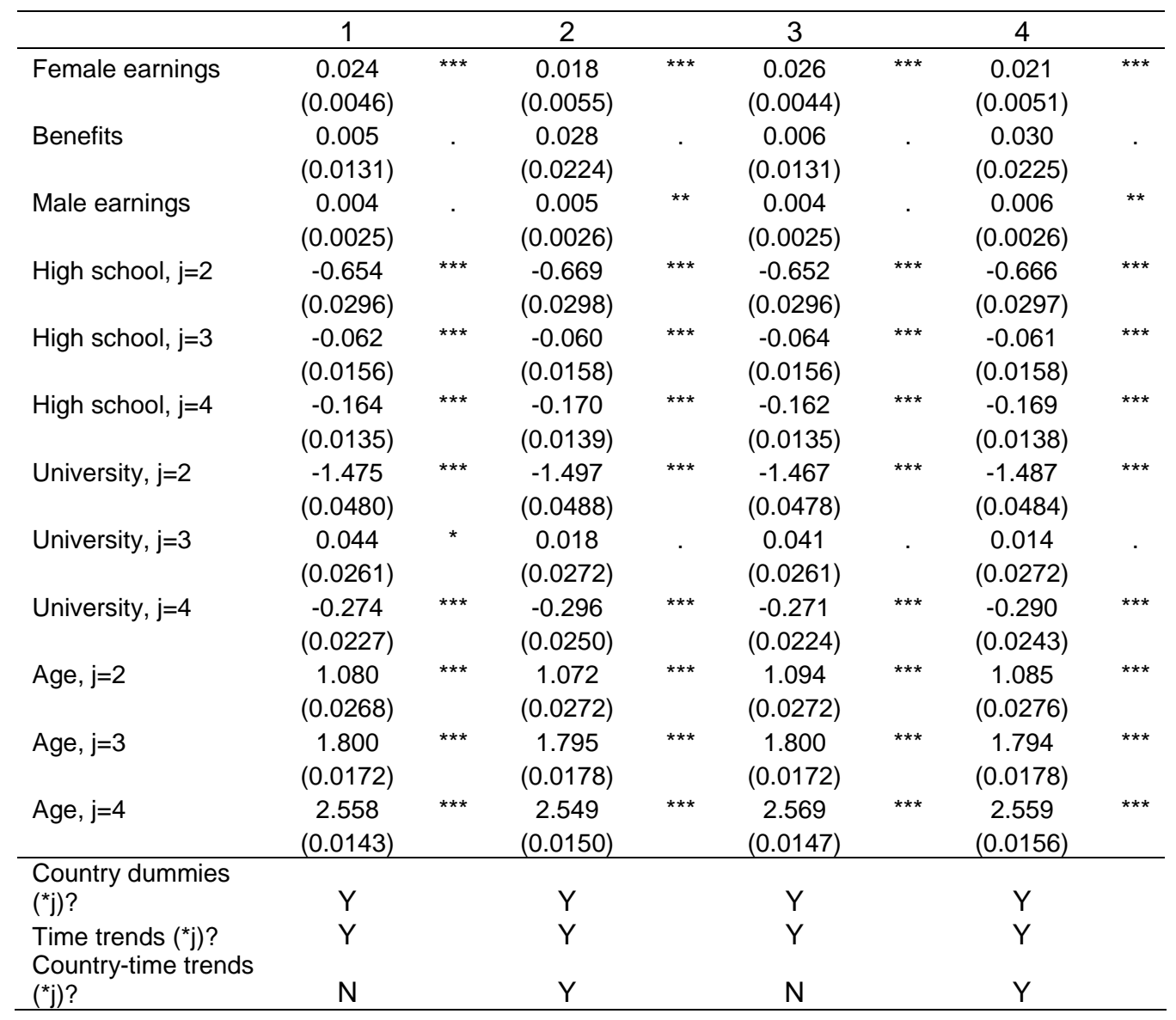

Note: Coefficients and standard errors (in parentheses) are shown. Pooled data for 14 countries, 5 periods. Sample size is 295,254. The analysis includes all women aged 18 to 45 . Three asterisks indicate significance at the $99 \%$ confidence level, two indicate significance at the $95 \%$ confidence level, and one indicates a 90\% confidence level. Specifications 1 and 2 use a measure of expected wages calculated using data for all women (by country, year, education and age), while columns 3 and 4 show the results when using an alternative measure of wages calculated with the subsample of single, childless women. 
Table 5. Marginal Effects from Conditional Logit

\begin{tabular}{|c|c|c|c|c|c|c|}
\hline & $\begin{array}{c}\text { Never } \\
\text { Married M. }\end{array}$ & & $\begin{array}{l}\text { Divorced } \\
\text { Mothers }\end{array}$ & & $\begin{array}{c}\text { All Single } \\
\text { Mothers }\end{array}$ & \\
\hline Female wage (\$/hour) & $\begin{array}{c}-0.144 \\
(0.0069)\end{array}$ & $\star \star \star *$ & $\begin{array}{c}-0.100 \\
(0.0535)\end{array}$ & * & $\begin{array}{c}-0.244 \\
(0.0540)\end{array}$ & 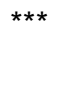 \\
\hline $\begin{array}{l}\text { Benefits single } \\
\text { mothers } \\
\text { (\$1000/year) }\end{array}$ & $\begin{array}{c}0.625 \\
(0.0724)\end{array}$ & $\star * *$ & $\begin{array}{c}0.092 \\
(0.0178)\end{array}$ & $\star * *$ & $\begin{array}{c}0.717 \\
(0.0745)\end{array}$ & $\star \star \star *$ \\
\hline $\begin{array}{l}\text { Benefits all families } \\
\text { with children } \\
(\$ 1000 / \text { year })\end{array}$ & $\begin{array}{c}0.365 \\
(0.0774)\end{array}$ & $* \star *$ & $\begin{array}{c}0.848 \\
(0.0743)\end{array}$ & 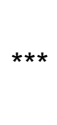 & $\begin{array}{c}1.213 \\
(0.1073)\end{array}$ & $* * *$ \\
\hline $\begin{array}{l}\text { Male earnings } \\
\text { (\$1000/year) }\end{array}$ & $\begin{array}{c}-0.061 \\
(0.0040)\end{array}$ & $\star \star *$ & $\begin{array}{c}0.058 \\
(0.0036)\end{array}$ & $\star * \star$ & $\begin{array}{c}-0.003 \\
(0.0054)\end{array}$ & . \\
\hline Male employment & $\begin{array}{c}-1.779 \\
(0.1305)\end{array}$ & $\star * *$ & $\begin{array}{c}1.640 \\
(0.1163)\end{array}$ & $\star \star *$ & $\begin{array}{c}-0.139 \\
(0.1748)\end{array}$ & . \\
\hline $\begin{array}{l}\text { Alimony/child support } \\
\text { (\$1000/year) }\end{array}$ & $\begin{array}{l}-0.009 \\
(0.0007)\end{array}$ & $\star * *$ & $\begin{array}{c}0.028 \\
(0.0020)\end{array}$ & $\star \star \star$ & $\begin{array}{c}0.018 \\
(0.0021)\end{array}$ & $\star \star \star *$ \\
\hline
\end{tabular}

Note: Average derivatives and standard errors (in parentheses) are shown. Pooled data for 14 countries, 5 periods. Sample size is 295,254. The analysis includes all women aged 18 to 45. Three asterisks indicate significance at the $99 \%$ confidence level, two indicate significance at the $95 \%$ confidence level, and one indicates a 90\% confidence level. The specification includes country dummies and country-specific time trends. 